\title{
Cartas científico-clínicas
}

\section{Leiomioma de la cápsula renal: presentación de un caso y revisión de la literatura}

\section{Leyomioma of the renal capsule: A case report and literature review}

\section{Sr. Director:}

Los tumores mesoteliales son un hallazgo excepcional en el tracto urinario. El leiomioma es el más frecuente de ellos y puede generarse en cualquier órgano que contenga músculo liso. Las exploraciones radiológicas no permiten distinguirlo inequívocamente de otros tumores renales malignos. Debido a su excepcional incidencia, son pocas veces incluidos dentro del diagnóstico diferencial de las masas renales, a pesar de alcanzar un tamaño considerable. Por ello, el diagnóstico suele realizarse mediante el análisis histológico de la pieza quirúrgica, como en el caso que presentamos.

Se trata de una mujer de 44 años con antecedentes de alergia a penicilina e intervenida quirúrgicamente hace varios años de apendicetomía y miomectomía, remitida a nuestra consulta por el hallazgo incidental de una masa renal izquierda tras la realización de una ecografía abdominal. En la exploración física el abdomen era blando y depresible, sin signos de irritación peritoneal, con puñopercusión renal y Guyon bilateral negativos. Los análisis de sangre y orina sólo revelaban hematuria microscópica. En la ecografía abdominal se apreció la existencia de una masa sólida en el polo superior del riñón izquierdo. La tomografía axial computarizada (TAC) confirmó este hallazgo, evidenciándose una tumoración dependiente de la cortical del polo superior del riñón izquierdo, con unas dimensiones aproximadas de $32 \times 23$ $\mathrm{mm}$, con discreta hipocaptación compatible con oncocitoma, sin poder descartar carcinoma renal. No se observaba afectación vascular, adenopatías retroperitoneales ni pélvicas. Con el diagnóstico de presunción de hipernefroma renal izquierdo se realizó tumorectomía renal laparoscópica izquierda. La biopsia del lecho renal intraoperatoria fue negativa. El postoperatorio cursó favorablemente, siendo dada de alta en el segundo día del mismo. La pieza fue remitida al Servicio de Anatomía Patológica, que tras el estudio macro (fig. 1) y microscópico (fig. 2) informó la pieza como leiomioma capsular. En el estudio inmunohistoquímico las células expresaban positividad para actina y desmina, y negatividad para citoqueratinas, S-100 y HMB-45.
Tras un seguimiento de 7 meses la paciente se encuentra asintomática y libre de enfermedad.

Los leiomiomas están incluidos dentro del grupo de tumores benignos con origen en el tejido conjuntivo o mesenquimal, y pueden implicar cualquier órgano del aparato genitourinario que presente músculo liso en su estructura histológica.

Así, se han descrito leiomiomas asentados en el útero, el riñón, la pelvis, el uréter, la vejiga, la uretra, las vesículas seminales, la próstata, el epidídimo, la albugínea, los testículos, el pene y el escroto ${ }^{1}$. Los leiomiomas renales son tumores de escasa frecuencia, aunque en series post mortem representan el segundo lugar en tumores mesenquimatosos renales después del fibroma intramedular ${ }^{2}$. En la literatura nacional son pocos los casos descritos ${ }^{3-9}$. Son tumoraciones cuyo origen se sitúa en áreas con músculo liso como: cápsula renal (37\%), pelvis renal (17\%), vasos corticales $(10 \%)$ y otras áreas no bien definidas (37\%).

El leiomioma renal se clasifica en tres tipos según su localización: subcapsulares (53\%), tumores pequeños, múltiples, asintomáticos, que suelen encontrarse incidentalmente en autopsias; capsulares, que son lesiones grandes, solitarias y generalmente sintomáticas (37\%); y leiomioma de la pelvis renal (10\%), extremadamente raro, con sólo 7 pacientes encontrados en la literatura.

Se presentan con mayor frecuencia como tumores pequeños $(<2 \mathrm{~cm})$, corticales, múltiples y asintomáticos; y en menor proporción como tumores solitarios y voluminosos. Son más frecuentes en mujeres (66\%) y en pacientes de raza blanca (70\%), siendo más común su hallazgo entre la segunda a quinta décadas de la vida. El modo más habitual de presentación es como masa palpable (57\%) y/o dolor en el flanco (53\%). La clásica tríada del carcinoma renal (dolor, masa abdominal y hematuria) se encuentra únicamente en el 3,3\% de los $\operatorname{casos}^{10}$. El leiomioma también se ha asociado a la esclerosis tuberosa, si bien las lesiones renales que más frecuentemente acompañan a esta son los angiomiolipomas y los quistes. El tumor no presenta predominio de lateralidad, 


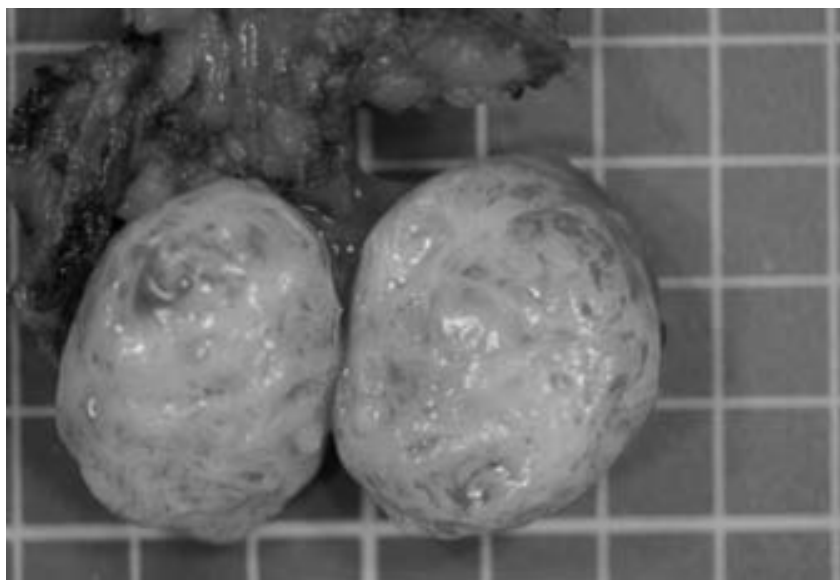

Figura 1- Pieza de nefrectomía parcial en la que se identifica un nódulo firme que mide 3,5 × 2, 5 × $2 \mathrm{~cm}$ de diámetro máximo acompañado de $4 \mathrm{~cm}$ de tejido adiposo. $\mathrm{Al}$ corte se observa un parénquima blanquecino de consistencia elástica con aspecto fascicular.

y se localiza en el $74 \%$ de las ocasiones en el tercio inferior del riñón. Suele tener un aspecto sólido (73\%), pudiendo sufrir ocasionalmente una degeneración quística (leiomioma quístico), no siempre relacionada con una degeneración sarcomatosa. La hemorragia aparece en el $17 \%$ de los casos y en un $20 \%$ se encuentran calcificaciones irregulares. Los leiomiomas de pequeño tamaño (menores de $2 \mathrm{~cm}$ ), múltiples frecuentemente, de localización subcapsular, constituyen generalmente hallazgos de autopsia. Es el grupo más frecuente, siendo excepcional su hallazgo clínico.

Los leiomiomas de gran tamaño, únicos y sintomáticos, son extremadamente raros $^{8}$.

La escasa frecuencia de estos tumores renales no ha permitido describir unos patrones radiológicos específicos, lo cual ha conducido a la realización de cirugía radical en numerosas ocasiones ante el diagnóstico de hipernefroma.

La TAC muestra ciertas características del leiomioma renal, sospecha que se incrementa ante el hallazgo de voluminosas masas renales en mujeres jóvenes asintomáticas, en ausencia de extensión locorregional o a distancia. La TAC anuncia lesiones bien circunscritas, de predominio periférico capsular o peripiélico, de naturaleza sólida con densidad de partes blandas, aunque en ocasiones quísticas, en ausencia de invasión en vecindad, afectación ganglionar ni visceral sistémica. Los leiomiomas, debido al componente predominante de músculo liso, reflejarían densidades de tejidos blandos (45 $\mathrm{UH})$ inferiores a las registradas en los hipernefromas (60-80 UH), como sucedió en nuestro caso. El eco-doppler, la angiorresonancia y la TAC helicoidal se utilizan para arrojar información vascular y anatomotopográfica de estos tumores. Tienen un pronóstico excelente, aunque se ha descrito una metástasis de las mismas características histológicas.

Macroscópicamente, el leiomioma aparece como un tumor sólido, de consistencia elástica al estar formado por músculo y colágeno, bien delimitado, de color blanco-nacarado, blancogrisáceo o rojizo al corte, dependiendo de la vascularización que presente, y de aspecto fascicular, que difiere del clásico

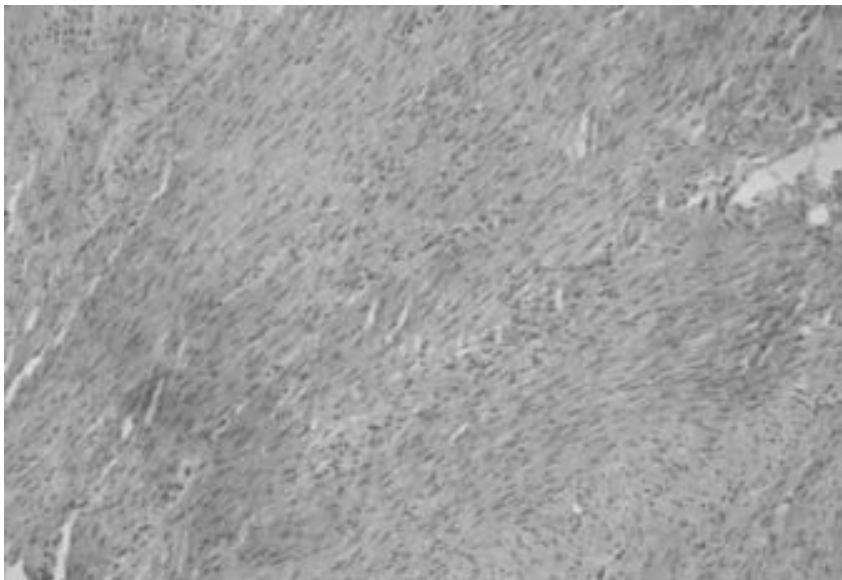

Figura 2- En el leiomioma destaca la presencia de células fusiformes dispuestas en haces separados en el seno de un estroma laxo hialinizado (crecimiento fascicular). Destaca la ausencia de mitosis y otros signos de malignidad.

color amarillento del carcinoma de células renales y del color canela de los oncocitomas. Inmunológicamente los leiomiomas muestran reactividad para vimentina, actina, miosina muscular lisa, desmina y componentes de la membrana basal, incluyendo laminina y colágeno tipo 4 y negatividad a las citoqueratinas de bajo peso molecular (BDK, AE1). Algunos autores demuestran que la expresión de HMB-45 determina el origen del tumor en la cápsula renal frente a los leiomiomas asentados en la pelvis renal. De manera adicional, permite diferenciarlos del leiomiosarcoma, que expresa negatividad a HMB-45, anunciando su carácter benigno en caso contrario. La positividad al HMB-45 se ha descrito fundamentalmente en tumores de origen hamartomatoso, como el angiomiolipoma, el rabdomioma y el linfangiomioma.

El análisis microscópico revela la presencia de células fusiformes dispuestas en haces separados en el seno de un estroma laxo hialinizado. Destaca la ausencia de mitosis y otros signos de malignidad, no obstante algunos autores han descrito su degeneración sarcomatosa y mixomatosa. Por ello, el diagnóstico diferencial se debe realizar con el leiomiosarcoma, el fibroma, el angiomiolipoma, el nefroma mesoblástico congénito, el carcinoma renal sarcomatoide $\mathrm{y}$, en los casos de leiomioma de pelvis renal, se debe diferenciar del schwanoma. Es conocida la asociación entre el virus de Epstein-Barr y la presencia de diferentes tumores en pacientes inmunodeprimidos, y entre ellos, los tumores del músculo liso. Estos han sido descritos en diversos órganos, entre ellos el riñón. Por ello, el leiomioma debe tenerse en cuenta a la hora de plantear el diagnóstico diferencial de una masa renal en este subgrupo de población.

El leiomioma renal es una tumoración infrecuente que debe incluirse en el diagnóstico diferencial de las masas renales. Se precisa un alto índice de sospecha ante el hallazgo en mujeres jóvenes asintomáticas, de voluminosas masas renales, bien delimitadas, de predominio periférico capsular o peripiélico, de naturaleza sólida con densidad de partes blandas y en ausencia de invasión en vecindad. Dado que 
la cirugía conservadora en el tratamiento del carcinoma unilateral de células renales es ciertamente una alternativa factible a la nefrectomía radical en pacientes con tumores de diámetro menor a $4 \mathrm{~cm}$, podríamos encontrarnos con el diagnóstico de leiomioma o de angiomiolipoma en la pieza procedente de esta cirugía parcial (como en nuestro caso). No obstante, considerando la dificultad que implica la sospecha clínica de estas neoplasias no será infrecuente que el diagnóstico se produzca tras el análisis histológico de una pieza de nefrectomía radical.

\section{B I B L I O G R A F Í A}

1. Belis J, Post G, Rochman S. Genitourinary leiomyomas. Urology. 1979;13:424.

2. Xipel JM. The incidence of benign renal nodules (a clinicopathologic study). J Urol. 1971;106:503.

3. Llamazares G, Ibarz L. Leiomioma renal en el adulto. Arch Esp Urol. 1980;4(5):269-72.

4. Cortadellas R, Castellanos RI, Guzmán A. Leiomioma de cápsula renal. Presentación de un caso y revisión de la literatura. Arch Esp Urol. 1992;45:478-80.

5. Montoya MD, García PJ, Gutiérrez JM. El leiomioma renal sintomático. Arch Esp Urol. 1993;46:833-5.
6. Rabade CJ, Fernández JM, Álvarez S. Leiomioma renal. Aportación de un nuevo caso. Actas Urol Esp. 1994;18:816-8.

7. Pereira Arias JG, Ullate Jaime V, Gutiérrez Díez JM, Ateca Díaz-Obregón R, Ramírez Rodríguez MM, Etxezarraga Zuluaga $\mathrm{MC}$, et al. Leiomioma renal voluminoso. Actas Urol Esp. 2001;25(1):81-5.

8. Clemente Ramos LM, Candia Fernández A, Allona Almagro A. Leiomioma renal sintomático: una masa de difícil diagnóstico. Actas Urol Esp. 2003;27(7):546-50.

9. Gómez Pérez L, Budía Alba A, Delgado Oliva FJ, Boronat Tormo F, Pontones Moreno JL, Jiménez Cruz JF. Leiomioma de pelvis renal. Actas Urol Esp. 2006;30 (6):641-3.

10. Steiner M, Quinlan D, Goldman S, Millmond S, Hallowell MJ, Stutzman RE, et al. Leiomyoma of the kidney: presentation of 4 new cases and the role of computerized tomography. J Urol. 1990;143:994-8.

M. Álvarez Maestro ${ }^{\mathrm{a}^{*}}$, L. Martínez-Piñeiro ${ }^{\mathrm{a}}$,

P. Domínguez Franjob ${ }^{b}$ E. Ríos Gonzáleza ${ }^{a}$

F.J. Sánchez Gómez y A. Linares Quevedoa aServicio de Urología, bServicio de Anatomía Patológica, Hospital Infanta Sofía, Madrid, España

*Autor para correspondencia. Correo electrónico: malvarezmaestro@htmail.com (M. Álvarez Maestro) 